\title{
Findability och informationskompetens vid webbnavigation
}

\author{
Af Jonas Fransson
}

\begin{abstract}
I artikeln diskuteras relationen mellan användare, informationsobjekt, informationssystem och webben $i$ kombination med koncepten findability och informationskompetens. I alla definitioner av informationskompetens är en aspekt förmågan att på ett effektivt sätt skaffa sig tillgång till den information som behövs. Men all information är inte lika tillgänglig, även om den är publicerad och fritt tillgänglig på webben. Varje webbsida, eller annat informationsobjekt, har en grad av findability. Graden av findability är avhängigt av relationerna mellan objekt, informationssystem och webben. Sex delkoncept är identifierade: objektets karaktäristika, tillgänglighet, intern navigation, intern sökning, nåbarhet och webbprestige. Både informationskompetens och findability definieras som frågeoberoende aspekter vid sökning, och de samverkar på ett strukturellt plan.
\end{abstract}

\footnotetext{
Jonas Fransson er ph.d.-studerende ved Det Informationsvidenskabelige Akademi (jf@iva.dk)
}

\section{Inledning}

Utgångspunkten i artikeln är att navigation och sökning på webben inte enbart är beroende av användarens karaktäristika som informationskompetens, personlighet och motivation, och dennes informationsbehov, utan också sökningens kontext. Inte kontext i meningen informationspraktik eller social- och organisatorisk miljö, utan kontexten som uppstår i interaktionen med informationssystemet. Det överordnade informationssystemet är i det här fallet webben och oavsett var eller hur man söker på webben så befinner man sig i en kontext, på en webbplats med ett specifikt innehåll.

Artikeln försöker att begreppsmässigt avtäcka begreppet findability, utifrån informationskompetens och informationssökning å ena sidan och systemegenskaper å andra.

Webben är ett stort och komplext informationssystem bestående av otaliga lokala informationssystem sammankopplade i ett nätverk, Internet. Därför är navigation och sökning på webben komplexare än det är i ett enskilt informationssystem, t.ex. en webbplats eller en databas.

I informationssystemen, eller informationsrummen, interagerar användarna med olika funktioner och reagerar på information som de stöter på. En modell som beskriver detta är Bates Berrypicking, där interaktionen liknas med bärplocking (Bates, 1989). Ett exempel på webben är användningen av Google. Där 
man först interagerar med sökmotorn, skriver in ett eller flera sökord och trycker därefter på sök-knappen, för att sedan reagera på den träfflista som kommer upp som resultat. För att bedöma träfflistan sätts många aspekter av informationskompetens i spel, men det ligger utanför denna artikel. Det är beteendet i sig som är intressant, det frekventa användandet av sökmotorer i allmänhet och Google i synnerhet för många olika syften. I och med sökmotoranvändandet så blir Google mediär, mäklare av information på webben (Halavais, 2009).

Men vad är det som återfinns i söktjänster som Google? Eller vid surfning på webben utan någon söktjänst som navigationshjälpmedel? Är all information på webben jämlik? Lika lätt att få tillgång till, att lokalisera? Nej, webben är en stor mängd länkade dokument. Länkarna är inte jämt fördelade, dokumenten har olika form och innehåll och de är publicerade i olika typer av webb informationssystem med olika syfte. Det är här begreppet findability kommer in (findability kan översättas till "hittbarhet" på svenska).

Men vad är egentligen findability? Säger det någon om personen som söker information? Mäter det några aspekter hos informationssystemet, eller kanske rent av egenskaper hos objekten som innehåller information? Det finns få direkta definitioner av findability. Indirekt kan olika syn på begreppet utläsas, speciellt i relation till andra närliggande begrepp som retrievability (återfinning i en databas) och accessibilty (tillgänglighet) (Azzopardi \& Vinay, 2008; Azzopardi \& Bache, 2010; Bashir \& Rauber, 2009; Morville, 2005).

Informationssökning och navigation ses i artikeln som Wilsons information searching, dvs. handlingar och interaktioner under en session (Wilson, 1999). Information ses här som ett ting (Buckland, 1991). All information är lagrad i någon form av informationssystem. Analoga exempel på informationssystem är boken och almanackan, och de har digitala motsvarigheter. På webben finns webbplatser och webbsidor som visar information, information som ofta lagrats i webbpubliceringssystem och databaser. Information är tillgänglig på webben kommer härefter benämnas informationsobjekt eller objekt i artikeln. Informationsobjekten kan innehålla information i olika form, t.ex. text, ljud, video, bild eller programkod. Ingen distinktion görs mellan Webb
1.0, Webb 2.0 och sociala medier på webben. Objekten kan vara en post i bibliografisk databas eller ett tweet i Twitter, mekanismerna är desamma.

\section{Informationskompetens och webben}

Kompetens kan definieras som förmågan att tillämpa färdigheter och kunskaper för att utföra en uppgift (Wikipedia, 2011c). Informationskompetens är alltså ett komplex av kunskaper, färdigheter och förståelse kring information omsatta i praktiska situationer. Hur informationskompetent en person är i en given situation beror både på dennes förmågor och hur situationen ser ut.

En av många definitioner i listform av vad en informationskompetent person kan, och kanske den mest spridda är ACRL:s (The Association of College and Research Libraries), nedan i svensk översättning (Granqvist, 2003). En informationskompetent person kan:

1. Definiera omfattningen på den information som behövs

2. Effektivt få fram den information som behövs

3. Kritiskt värdera informationen och dess källor

4. Integrera utvald information i den egna kunskapsbasen

5. Använda information effektivt för att uppnå ett visst mål

6. Förstå de ekonomiska, juridiska och sociala aspekterna som sammanhänger med informationsanvändning samt söka och använda information på ett etiskt och lagligt sätt.

Artikeln fokuserar på punkt 2 i definitionen ovan, delkompetensen som rör sökning efter information. Delkompetensen är i det engelskspråkiga originalet formulerat som: "Access needed information effectively and efficiently." De två snarlika orden effectively och efficiently översätts till effektivt i definitionen ovan, men deras betydelse skiljer sig åt. Effectively är beskriver måluppfyllelse medan efficiently beskriver vägen till målet, t.ex. energiförbrukning (Wikipedia, 2011a). Vid informationssöknings resultat respektive hur sökningen genomförts.

Definitioner av informationskompetens likt den ovan bygger på en tradition av användarundervisning kring källor, sökteknik och värdering av information, främst vid bibliotek vid undervisningsinstitutioner 
(Limberg, Sundin, \& Talja, 2009). Definitionerna kan sägas utgå ifrån ett strukturerat paradigm där informationssökning av tradition skett i kontrollerade informationssystem, t.ex. bibliografiska databaser eller fysiska bibliotek, och sökexperter spelat en stor roll. Utvecklingen av nya informationssystem, främst webben, har lett fram till ett nytt paradigm, webbparadigmet, där informationssökningen är mer iterativ och görs av slutanvändarna själva (Pharo, 2008). Webben möjliggör genom sin hypertextstruktur också explorativ sökning i större grad än i mer traditionella informationssystem (White \& Roth, 2009).

Artikelns fokus ligger på den speciella kontext som webben utgör, och därmed främst på webbparadigmet. Gerjets och Hellenthal-Schorr har utvecklat en metod för träning av elevers informationssökningskompetens på webben. Som utgångspunkt för sitt arbete har de dekonstruerat olika definitioner av mediekompetens och informationskompetens och delat upp och grupperat de delkompetenser som definitionerna innehåller. Sedan har de sammanställt de fyra viktigaste delkompetenserna vid informationssökning på webben (Gerjets \& Hellenthal-Schorr, 2008, s. 696):

\section{- Media background knowledge: Background} knowledge with regard to the development and structure of the Internet and with regard to specific features of the WWW as information environment.

- Media operation skills: Skills for using computers, the Internet, and the WWW (e.g., how to connect to the Internet, how to use a browser software, how to use search engines and other web tools).

- Orientation skills: Ability to keep oriented with regard to the information sources provided by the WWW.

- Selection and evaluation skills: Ability to evaluate information provided in the WWW with regard to its relevance in the context of a current information problem as well as with regard to its quality and credibility. Ability to select information according to these evaluation criteria.

Informationskompetens ses här som ett generiskt koncept eftersom det är en tillämpning av de färdigheter och kunskaper som kompetensen omfattar. Det generella ligger i konceptet, och utan överförbarhet mellan t.ex. olika medier, mister begreppet delar av sitt värde. Samtidigt är varje situation där informa- tionskompetensen används unik och därmed kommer olika kombinationer av kunskaper och färdigheter i spel varje gång. Det innebär att individens verkliga informationskompetensnivå varierar beroende på situation.

\section{Informationssökningsprocessen}

Sökprocessen är det som sker i mötet, i interaktionen, mellan användare och informationssystem. Användaren inleder interaktionen med att ha en intention, ett informationsbehov i bred förståelse. Behovet kan vara explicit och väl definierat, men det kan också vara mycket otydligt. Användaren vill få reda på något, hitta ett svar, lokalisera ett objekt eller komplettera sin kunskap. För att lösa sitt informationsbehov påbörjar användaren en informationssökning (Ingwersen \& Järvelin, 2005). Men hur förhåller sig informationskompetens till informationssökning?

Marchionini beskriver informationskompetens som en uppsättning färdigheter och koncept, medan informationssökning är en grundläggande mänsklig process. Att utveckla de studerandes förståelse av informationssökningsprocessen blir därmed en av de centrala delarna i undervisning i informationskompetens (Marchionini, 1999).

Informationssökningsprocessen består av åtta delprocesser enligt Marchionini (1995):

1. Upptäcka och acceptera

2. Definiera problem

3. Välja söksystem

4. Formulera frågan

5. Utföra sökning

6. Utvärdera resultat

7. Utvinna information

8. Reflektera och avsluta

Delprocesserna sker inte nödvändigtvis i ett linjärt förlopp, utan övergångarna mellan delprocesserna kan skifta. Hur delprocesserna genomförs beror på den personlig informationsinfrastruktur som människor utvecklar, en infrastruktur som består av flera delar (Marchionini, 1995):

- Mentala modeller för kunskapsdomäner, söksystem och tidigare informationssökningar

- Generella kognitiva färdigheter och informationssökningsspecifika färdigheter 
- Attityder och mentala kontrollmekanismer

- Materiella resurser som tid, pengar och utrustning.

Kopplingen mellan den personliga informationsinfrastrukturen, som beskrivs ovan, och informationskompetens beskriver Marchionini som följer (1999):

"Our personal information infrastructures are applied to information problems in an array of contexts and continue to evolve as a result of our struggles with and conquests of these problems. The development of our personal information infrastructure is roughly equivalent to our level of information literacy. Thus, information literacy is best considered to be a continuum of skills, concepts, attitudes, and experiences related to information access, understanding, evaluation, communication, application, creation, and value".

Marchioninis syn på informationskompetens innebär att förbättrade färdigheter och ökade kunskaper leder till förbättrad informationskompetens och därmed effektivare delprocesser vid informationssökning.

\section{Sökfråge-beroende och -oberoende aspekter}

En dimension $\mathrm{i}$ informationssökning är användaren kontra informationssystemet. På användarsidan talar vi om informationsbehov och informationskompetens, och på systemsidan den inbäddade informationen och webbens komplexitet. En annan dimension är frågan om vilka delar som är sökfråge-oberoende (query independent) vid informationssökning. Användarens aktuella informationsbehov skapar en sökfråge-beroende (query dependent) kontext för informationssökningen. Men oavsett informationsbehov så är stora delar av informationen på webben inte relevanta vid varje specifik sökning, medan andra aspekter inte berörs av sökningens innehåll.

Detta kan exemplifieras med hur Google hanterar en vanlig sökning: När en sökfråga skickas till Google beräknar Google först vilka de innehållsmässigt mest relevanta webbsidorna är utifrån sökorden. Därefter bestämmer Google rankningen på de relevanta webbsidorna utifrån graden av relevans och länkarnas PageRank-värde. PageRank är Googles mått på en webbsidas prestige på webben, dvs. vilka som länkar till sidan och hur många som länkar till sidan. PageRank är ett kvantitativt mått som bygger på länkanalys och helt oberoende av sökorden (Brin \& Page, 1998).

Informationskompetens och dess delkompetenser beskriver Gerjets och Hellenthal-Schorr vanligtvis som oberoende av både medium och användarens mål (Gerjets \& Hellenthal-Schorr, 2008, s.696):

"These sub-competencies are usually conceived as being independent of the specific medium used and of users' goals in the context of media utilization."

De centrala kompetenserna vid informationssökning på webben möjliggör informationssökningen, men är generella. Informationskompetensen är skild från informationsbehovet och sökningens ämne. Ämneskunskaper relevanta för informationsbehovet kommer naturligtvis i spel. Men forskning tyder på att kunskaper inom ämnesområdet (domain knowledge) bara påverkar sökbeteendet, inte sökningens effektivitet (Zhang, Anghelescu, \& Yuan, 2005).

Samma uppdelning mellan sökfråge-beroende och sökfråge-oberoende aspekter kan göras på informationssystemsidan. Innehållet i informationsobjekten och deras representation i form av exempelvis metadata är den information som användaren matchar mot sitt informationsbehov, och därför kan de ses som en sökfråge-beroende aspekt. Representationen av objekten, metadatans innehåll, måste matcha någon del av informationsbehovet för att det ska upplevas som relevant av användaren. I Information foraging theory används begreppet information scent för när användaren bedömer ledtrådarna till eller representationen av ett potentiellt relevant objekt. Genom "doften" som ledtrådarna avger, t.ex. länktexter på en webbsida, så väljs den som troligast leder mot målet, dvs. den som har starkast doft (Pirolli, 2007). Om doften avtar kan bakåtknappen i webbläsaren användas för att från en tidigare besökt sida följa ett alternativt doftspår, eller så påbörjas istället en ny sökning.

Hur tillgängliga objekten är tekniskt och strukturellt sett är en sökfråge-oberoende aspekt. Hur och var informationsobjekten och dess representationer är synliga i systemet och på webben är också viktigt ur ett fråge-beroende perspektiv. Mängden av metadata, inte metadatans innehåll, skapar en träffyta för informationssökare vid sökning i sökmotorer. En central aspekt på webben är att objekt har egna unika webb- 
adresser, URL:er, så de är nåbara direkt och inte kräver ytterligare en sökning $i$ en databas.

En annan viktig aspekt, som tidigare nämnts, är mängden länkar till objeken och länkarnas prestige på webben. Google kallar varje länk till en webbsida för en röst ( $a$ vote), men det är inte som i ett demokratiskt val där alla röster är lika mycket värda utan mer som en bolagsstämma i ett aktiebolag där rösterna räknas olika. En länk från en webbsida med hög prestige på webben är mer värd än en länk från en privat webbsida, dvs. länken får del av sidans höga PageRank (Sherman, 2005).

Förutom att objekten ska vara nåbara via länkar och helst vara länkade till från andra sidor så är en viktig aspekt huruvida objekten är indexerade av de generella sökmotorerna. För att objekten ska bli indexerade, och därmed sökbara, i t.ex. Google krävs att sökmotorn kan följa länkar till objekten, sökmotorn ska inte hindras av tekniska orsaker eller av policyskäl. Ett enskilt informationssystem kan lätt hindra indexering både medvetet och omedvetet.

\section{Findability}

Ovanstående sökfråge-oberoende aspekter avgör graden av findability på webben. Findability är inget entydigt begrepp. I engelskspråkiga Wikipedia definieras findability som följer (Wikipedia, 2011b):

"Findability is a term for the ease with which information contained on a website can be found, both from outside the website (using search engines and the like) and by users already on the website. Although findability has relevance outside the World Wide Web, it is usually used in the context of the web."

Wikipedias definition bygger i stor grad på Morvilles definition. Han definierar findability i boken Ambient findability som (Morville, 2005):

"1. The quality of being locatable and navigable.

2. The degree to which a particular object is easy to find or locate.

3. The degree to which a system or environment supports navigation and retrieval."

Enligt Morvilles definition opererar findability på olika nivåer, både på objektnivå (punkt 2) och på in- formationssystemnivå (punkt 3). Han talar också om "graden av findability" vilket betyder att findability kan sättas in på en skala. Morville diskuterar findability på ett generellt plan och tar inte upp webben specifikt, men i denna artikel syfta findability fortsättningsvis på findability på webben. Information på webben är publicerad i ett informationssystem (t.ex. ett content management system, en blogg eller en databas) och sedan är informationssystemet tillgängligt på webben. På grund av webbpubliceringens komplexitet är findability i ständig förändring. Men det är en ytterst central aspekt när det gäller information på webben i denna tid av stort sökmotoranvändande (Halavais, 2009).

I forskningen finns ännu ingen entydig definition av findability. Begreppet är relaterat till koncept som retrievability och sökbarhet. Retrievability används i information retrieval-forskning och mäter hur sannolikt det är för ett dokument att hittas med en bestämd uppsättning sökfrågor. Ibland används begreppen retrievability och findability som synonymer. Bashir och Rauber skriver (2009):

"In recent years measurement concepts like document "retrievability", "searchability" and "findability" emerged. These concepts measure, how retrievable each individual document is in the retrieval system, i.e. how likely it is that a document can be found at all given a specific set of queries"

Medan Azzopardi and Bache gör följande distinktion mellan findability och retrievability (2010):

"The accessibility of information in a collection given a system has been considered from two points of view, the system side i.e. retrievability and the user side findability. Retrievability measures provide an indication of how easily a document could be retrieved using a given IR system, while findability measures provide an indication of how easily a document can be found by a user with the IR system."

I artikeln diskuterar Azzopardi och Blanche inte skillnaden ytterligare. Ska findability ses som användarsidan av retrievability? Om retrievability är det mätbara systemperspektivet tillsammans med begrepp som precision och recall, inkluderar då findability användarens informationsbehov och grad av informationskompetens? 
Azzopardi och Vinay påpekar att det är krav på olika nivåer som måste uppfyllas för att findability kan uppnås i ett information retrieval system som en sökmotor. Dokumentet måste vara indexerat för att vara hittbart, det är det första kravet. Då kan dokumentet hittas genom sökning i systemet. Den andra nivån består av flera faktorer, matchningssystemet $\mathrm{i}$ retrieval-systemet, användarens förmåga att omvandla sitt informationsbehov till en lämplig sökfråga för systemet (informationskompetens), samt användarens motivation att titta genom många dokument eller träfflistor. Azzopardi och Vinay konkluderar att om man kombinerar dessa faktorer betyder det att vissa dokument är lättare att tillgå (easily accessible) än andra (Azzopardi \& Vinay, 2008). Här är användaren och dennes informationskompetens en explicit del av findability.

I linje med Morvilles definition men tvärtemot definitionerna i artiklarna av Azzopardi m.fl. definieras findability här som ett användarfritt och frågeoberoende begrepp. Detta eftersom det saknas begrepp för hittbarhet utöver retrievability ur ett webbperspektiv. För användarsidan har vi olika begrepp kring kunskaper, färdigheter, kompetenser och behov - det behövs inte ytterligare begrepp som innefattar flera redan svårfångade aspekter av mänskligt informationsbeteende. En definition av findability för webben baserad på Morvilles definition är:
"Findabilty är hur lätt det är att finna eller lokalisera ett enskilt objekt eller en enskild webbplats på webben, utifrån:

1. objektets karaktäristika;

2. design och inställningar $i$ det lokala informationssystemet (webbplatsen) vari objektet är publicerat eller lagrat;

3. objektets respektive webbplatsens prestige på webben i form av inlänkar."

Findability är ett mått för att mäta och jämföra hur hittbara (findable) olika objekt är. Hur hittbart ett objekt är för en enskild användare beror både på objektets grad av findability och på användarens informationskompetensnivå. Att söka efter och hitta objekt sker genom en användares aktiva handlingar. Findability däremot beskriver en grupp egenskaper hos objektet som kan hittas. I nästa avsnitt kommer detta tydliggöras i en modell.

\section{En modell}

Om de två begreppsparen användare/informationssystem och sökfråge-beroende/sökfråge-oberoende sätts samman så de skapar en tvådimensionell modell kan artikelns centrala koncept placeras in. I modellen (figur 1) ska begreppen informationsbehov/informationskompetens och representation/findability ses i kontexten av interaktionen mellan användare och system under en söksession.

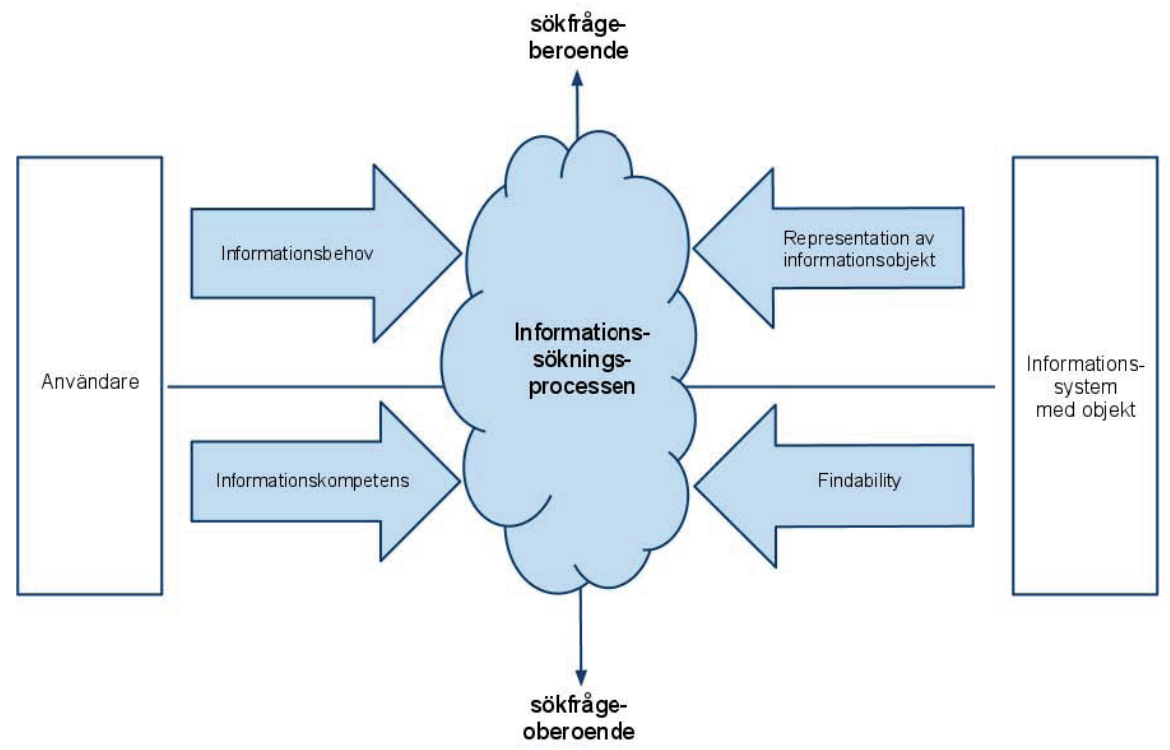

Figur 1. Modell över interaktionen mellan användare och informationssystem på webben. 
I modellens vänstra del finns användaren som går i informationssökningsprocessen med sitt informationsbehov och sin informationskompetens. De motsvaras av informationsobjektens representation och findability. I informationssökningsprocessen bearbetar och reagerar användaren på den feedback som webben och de lokala informationssystemen ger på användarens handlingar.

I den övre delen av modellen finns de delar av sökprocessen som handlar om informationsbehovet, sökfrågan och informationsobjektens innehåll samt deras representation, dvs. de sökfråge-beroende delarna. I den undre delen återfinns de sökfråge-oberoende, mer strukturella delarna informationskompetens och findability.

Trots att pilarna är riktade mot varandra ska de inte ses som i motsättning till varandra. Tvärtom så kompletterar de varandra på respektive nivå i modellen, de är ingångsvariabler i informationssökningsprocessen. Användare med låg informationskompetens hittar med högre sannolikhet objekt med hög findability, än objekt med låg findability, under förutsättningen att båda objekten uppfattas som relevanta.

I modellen kan pilarnas längd illustrera graden av informationskompetens och findability, respektive klarheten och specificiteten i informationsbehovet och representationen av/innehållet i objekten. Det tydliggör att låg informationskompetens innebär att endast objekt med hög findability hittas. Användaren har färre sökstrategier att använda och mindre effektivitet i alla av informationssökningsprocessens delprocesser. På samma sätt kräver objekt med låg findability en större informationskompetens hos användaren för att de ska hittas eller nås.

Modellen gör inga anspråk på att beskriva hela komplexiteten vid navigation eller sökning på webben. Poängen med modellen är att den delar upp ingångsvariablerna i två grupper: sökfråge-beroende och sökfråge-oberoende, samt att separera användaren från begreppet findability. Modellen tar inte hänsyn till strukturella aspekter av social, affektiv eller personlig karaktär, men de kan ses som en del av informationskompetensen i sökögonblicket. Inte heller tar modellen hänsyn till informationsbehovsspecifika aspekter såsom motivation och ambition, de kan ses som aspekter av ett flerdimensionellt informationsbehov.
Om modellen ses i en mer generell kontext så är det många som arbetar med att överbrygga glappet mellan bristande informationskompetens och låg findability. Informationsarkitekter arbetar med navigation och sök på webbplatser. Sökmotor-optimerare kämpar med att optimera webbsidor för så hög rankning som möjligt i sökmotorerna. Bibliotekarier och andra informationsspecialister agerar som "kompensatörer" och mediärer mellan samlingarnas låga findability och användarnas otillräckliga informationskompetens. De har också i allt högre grad som uppgift att träna användarnas informationskompetens genom undervisning.

\section{Navigation på webben}

Sättet som informationsobjekt presenteras på beror delvis på dess inneboende egenskaper och innehåll. Men presentationen av objekten beror också på informationssystemet, hur det är utformat och dess inställningar. Objekten kan sägas vara inbäddade $\mathrm{i}$ informationssystem och är beroende av informationssystemet för att vara tillgängliga och hittbara för användarna.

På webben tillkommer ytterligare en dimension: informationssystemet och dess innehåll är tillgängligt via Internet $i$ ett större informationssystem med en annan underliggande struktur och logik - webben. Beroende på de enskilda informationssystemens arkitektur är de objekten tillgängliga i olika grad direkt på webben. En del informationssystem kräver att man söker direkt i dem för att få tillgång till dess objekt. Nedanstående illustrationer visar problematiken ur två olika synvinklar.

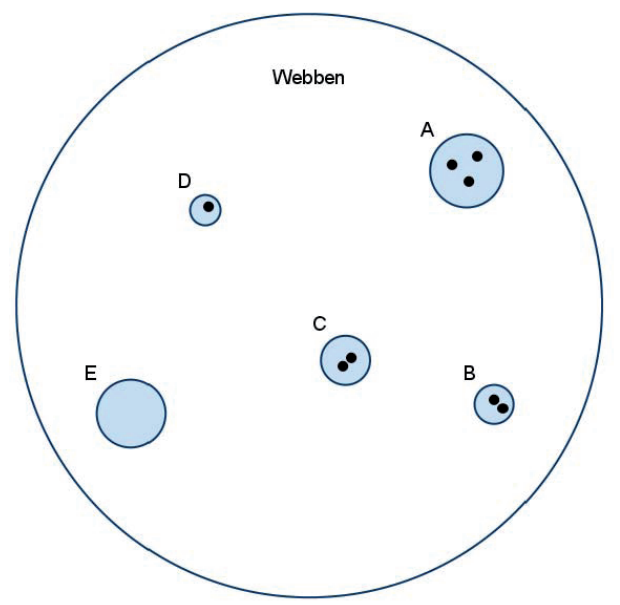

Figur 2. Objekt och lokala informationssystem ur ett webbperspektiv. 
Bilden illustrerar fem webbplatser (A-E) ur ett webbperspektiv (den stora cirkeln), där A och E är stora webbplatser och B-D mindre webbplatser. Prickarna i A-D illustrerar att objekt på webbplatserna är möjliga att nå direkt från webben. Avsaknaden av prickar $\mathrm{i} \mathrm{E}$ betyder att dess innehåll nås endast från webbplats E, t.ex. för att objekten saknar unika URL:er. Det här perspektivet belyser hur mycket användaren har att välja på samtidigt som en del objekt inte kan nås direkt, utan sökningen måste ske i flera steg. Olika sökstrategier behövs för att nå objekten som är tillgängliga på webben (A-D) respektive via webben (E). För ett objekt på webben kan en enkel sökning i Google vara tillräckligt för att komma till det. Objekt som endast är tillgängliga via webben kräver en sökning i flera steg. Först en sökning för nå webbplatsen där objektet finns och sedan en andra sökning på webbplatsen för lokalisera det enskilda objektet. Det sistnämnda söksättet kan kallas två stegs sökning eller indirekt sökning (Fransson, 2007).

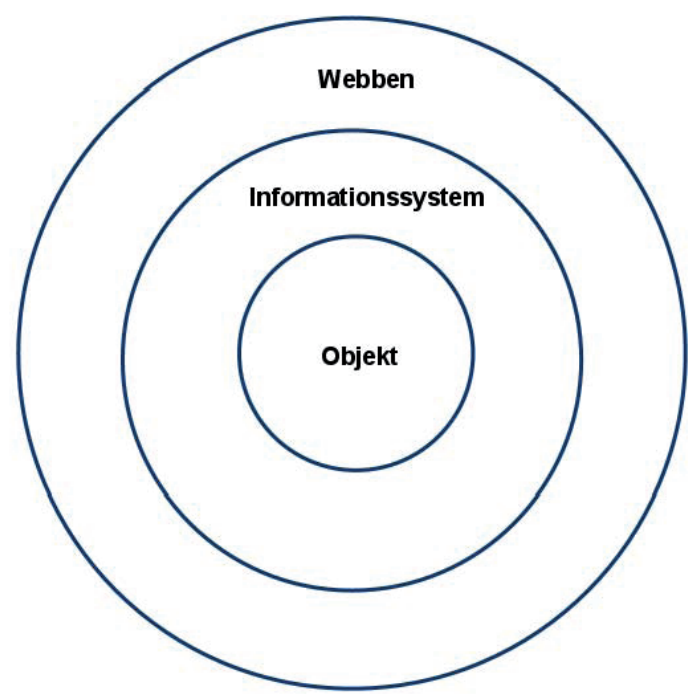

Figur 3. Objekt är inbäddade i informationssystem och webben.

Webbplatserna i figur 2 kan också illustreras ur ett objektperspektiv. I figur 3 är objekten i fokus och de är inbäddade av två kringliggande lager, informationssystem och webben. Till en del beror antalet användare som hittar fram till objekten i olika informationssystem på yttre faktorer, faktorer i de kringliggande lagren. Det kan handla om att webbplatsen har en dålig intern sökmotor eller att den har få länkar från andra webbplatser.
I artikeln används begreppen navigation och att navigera för att söka, lokalisering och tillgå (access) information. Navigation täcker in de andra begreppen och är neutralt i förhållande informationsbehov. Det finns tre huvudsakliga navigationsstrategier på webben (Levene, 2010; Nachmias \& Gilad, 2002):

1. Direkt navigation. Det enklaste sättet att navigera är att skriva in en URL i webbläsaren. Den har strategin inkluderar även andra sätt att ta sig till redan kända destinationer, som t.ex. att följa ett sparat bokmärke i webbläsaren eller tidigare besöka sidor webbläsarens historik.

2. Navigation via länkar. Att följa länkar i hypertexten utnyttjar webbens natur. Tidigare var mänskligt redigerade kataloger med länkar centrala för informationssökning på webben, medan nu har andra typer av webbplatser intagit deras position, t.ex. bloggar, bokmärkestjänster (t.ex. Delicious) och Wikipedia.

3. Navigation genom användning av en sökmotor. Sökmotorer används både för att navigera till kända platser på webben och för att söka efter ny information. "Traditionella" sökfrågor är bara en av flera typer av sökningar som sökmotorerna försöker ge relevants svar på.

Användningen av de tre strategierna varierar över tid och beror på webbens utveckling. Under webbens första år, innan sökmotorer som Altavisa och Google, var navigation via länkkataloger som Yahoo den kanske vanligaste strategin. Under 1990-talet var fortfarande informationsmängderna på webben små, så de centrala delarna på webben kunde katalogiseras. Nu utgörs webben av enorma mängder av information publicerad på webbservrar. Det är inte känt hur stor webben är. Storleken har uppskattats på olika sätt, i antal webbsidor eller i terabyte. En uppskattning som gjorts nyligen är 600 miljarder indexerbara sidor (Levene, 2010). 2008 hade Google upptäckt en biljon unika URL:er (Alpert \& Hajaj, 2008). Och den växer fort.

Sedan 90-talet har de generella sökmotorerna blivit den viktigaste typen av söktjänster på webben. De har blivit webbens grindvakter (gatekeepers), de har till och med kallats webbens drakar (Witten, Gori \& Numerico, 2006). Men allt är inte indexerat av sökmotorerna. Två olika begrepp används för den information som inte återfinns i sökmotorerna: osynliga webben och djupa webben. Osynliga web- 
ben är den del av webben som inte är indexerad av sökmotorerna, och därmed är informationen osynlig i den aktuella sökmotorn - osynligheten är olika för varje sökmotor. Den djupa webben är motsatsen till den grunda, lättindexerade ytwebben som består av webbsidor i (x)html. Den djupa webben utgörs av information som är lagrad i databaser och som bara presenteras dynamiskt när den eftersöks. Exempel på webbsidor med dynamiskt genererat innehåll är aktiekurser och lediga flygstolar. Sökmotorerna kan inte genomföra sökningar och därmed är informationen begravd för djupt för indexering. Informationen kan också vara i format som är svåra eller omöjliga att indexera, som bilder, video, program eller packade filer (Bergman, 2001). Under de senaste åren har de två koncepten blivit mindre distinkta i och med att sökmotorerna har blivit mer tekniskt avancerade och lagrar större mängder data i sina index (Fransson, 2007).

För att nå informationsobjekten måste användaren ta sig genom webben till informationssystemet som innehåller objekten genom att använda någon av de tre strategierna som beskrivits ovan. Varje strategi kan leda både till ett objekt och till informationssystemets startsida. Strategierna är uppdelade i externa och interna strategier. De externa strategierna täcker navigation från webben till informationssystem och objekt, medan de interna strategierna rör navigationen från informationssystem till objekt, t.ex. inom en webbplats. Om strategierna delas in i steg så ser de ut som följer:

\begin{tabular}{|c|c|c|c|}
\hline Webbnavigations-strategi & Steg 1 & Steg 2 & Steg 3 \\
\hline \multirow[t]{2}{*}{ Direkt navigation (1) } & Känd URL till objekt (a) & Nå objekt & \\
\hline & Känd URL till system (b) & Nå system* & \\
\hline \multirow[t]{2}{*}{ Navigation via länkar (2) } & Följa länk till objekt (c) & Nå objekt & \\
\hline & Följa länk till system (d) & Nå system* & \\
\hline \multirow[t]{2}{*}{$\begin{array}{l}\text { Navigation genom användning av en } \\
\text { sökmotor (3) }\end{array}$} & Söka i en sökmotor (e) & $\begin{array}{l}\text { Följa länk i träfflista till ob- } \\
\text { jekt (f) }\end{array}$ & Nå objekt \\
\hline & Söka i en sökmotor (e) & $\begin{array}{l}\text { Följa länk i träfflista till sys- } \\
\text { tem }(\mathrm{g})\end{array}$ & Nå system* \\
\hline
\end{tabular}

* Leder till interna navigationsstrategier för att nå objekt inom informationssystemet.

Tabell 1. Steg i externa navigationsstrategier (parenteserna hänvisar till figur 4).

\begin{tabular}{|l|l|l|l|}
\hline $\begin{array}{l}\text { Navigationsstrategi } \\
\text { inom informationssystem }\end{array}$ & Steg 1 & Steg 2 & Steg 3 \\
\hline Navigation via länkar (4) & $\begin{array}{l}\text { Följa länk till underkate- } \\
\text { gori (h) }\end{array}$ & $\begin{array}{l}\text { Följa länk till objekt (från } \\
\text { underkategori) (i) }\end{array}$ & Nå objekt \\
\hline $\begin{array}{l}\text { Navigation genom användning av intern } \\
\text { sökmotor (5) }\end{array}$ & Söka i intern sökmotor (j) & $\begin{array}{l}\text { Följa länk i träfflista till ob- } \\
\text { jekt (k) }\end{array}$ & Nå objekt \\
\hline
\end{tabular}

Tabell 2. Steg i interna navigationsstrategier (parenteserna hänvisar till figur 4).

Inom ett informationssystem på webben finns det minst ett av två sätt att navigera, via länkar eller med hjälp av en intern sökmotor. Vanligtvis finns båda de två navigationssätten implementerade, men t.ex. en OPAC eller annan typ av databas bygger på att användaren ska göra sökningar, där finns oftast ingen möjlighet att systematiskt klicka sig ner i innehållet.
Stegen i tabell 1 och 2 ovan blir konkretare när de sätts in i modellen där objekten är inbäddade i informationssystemet och webben (figur 4). Då blir det tydligare vad de olika navigationsstrategierna innebär, hur användaren rör sig mellan de olika lagren för att nå objekten. 


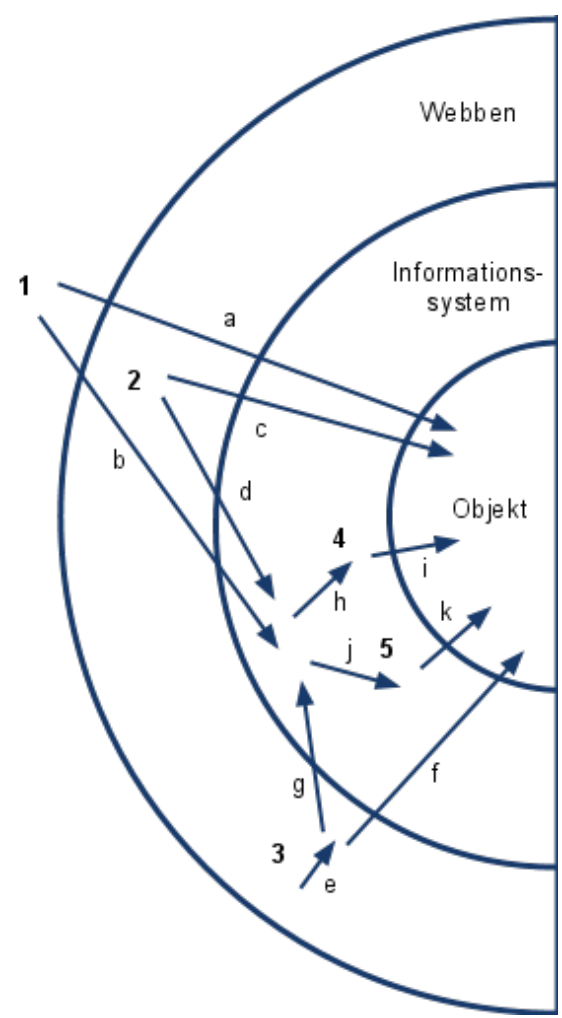

Figur 4. Navigationsstrategiernas väg genom webben och informationssystemet till objektet, jmfr tabell 1 och 2 .

Bokstäverna i figur 4 motsvarar ett steg i respektive strategi (tabell 1 och 2 ovan). Skillnaden mellan strategi 1 och strategierna 2 och 3 är att direkt navigation kan starta utanför webben. Det krävs ingen startsida för att skriva in en känd webbadress eller för att välja ett bokmärke i webbläsaren. Direkt navigation kan ske från vilken plats som helst på webben, i varje ögonblick kan användaren "teleportera sig" till en känd URL.

Varje pil kräver underbyggnad för att strategin ska vara effektiv i praktiken. Möjliga hinder i strukturen som låg findability innebär, kan kringgås av relevanta sökstrategier tillsammans med situationsanpassade taktiker. Kunskap om användning av taktikerna och strategierna i reella situationer är informationskompetens.

\section{Findability i praktiken}

Findability är ett begrepp som utgår ifrån ett systemperspektiv och tar med komplexiteten hos informa- tionsmiljön på webben. Begreppet beskriver, eller mäter, egenskaper hos det sammantagna informationssystemet, inklusive informationsobjektets egenskaper. Utifrån forskning och praxisrelaterad litteratur har jag identifierat sex centrala koncept, som alla utgör delar av webbfindability:

Objektets karaktäristik (object attributes) är informationsobjektets innehåll, dess form och format. Viktiga delar är eventuell fulltext, metadata och filformat. Textobjekt har andra förutsättningar än multimediaobjekt. Representationerna av objektet i de yttre lagren, i informationssystemets länkhierarki och interna sökmotor, och på webben i form av länktexten i inlänkar och beskrivningen i Googles träfflista bygger på objektets karaktäristik (Enge, 2009; Walter, 2008).

Tillgänglighet (accessibility) handlar om att informationen ska vara möjlig att tillgå. Egentligen fokuserar tillgänglighetsfrågor på personer med handikapp, men en handikappvänlig webbsida är också en sökmotorvänlig sida. Sökmotorerna har stora begränsningar i sitt sätt att tolka innehållet på webbsidor, på samma sätt som en talsyntes som läser upp webbsidors innehåll. Tekniker som flash eller javascript kan begränsa eller helt hindra tillgång till informationsobjekten. Accessibility är nära kopplat till usability (användarvänlighet) (Thatcher, 2006; Walter, 2008).

Intern navigation (internal navigation) är en central del inom ett informationssystem och handlar om länkstrukturer och möjligheten att följa länkar ner till enskilda objekt. På webbplatser är navigation via länkar det huvudsakliga sättet att navigera (Ding \& Lin, 2010; Morville \& Rosenfeld, 2007).

Intern sökning (internal search) är en möjlighet som allt fler informationssystem har, och det är det andra sättet att navigera inom en webbplats. Hur väl en intern sökmotor fungerar beror på sökmotorns prestanda och inställningar samt de indexerade objektens karaktäristik (Ding \& Lin, 2010; Morville \& Rosenfeld, 2007).

Nåbarhet (reachability) är ett krav för att både användare och sökmotorer ska komma till objektet. Finns inga länkar till objektet så blir det en isolerad ö på webben. Under begreppet nåbarhet faller även indexerbarhet för sökmotorer, så att objektet kan 
återfinnas vid sökning i sökmotorerna (Björneborn, 2004; Enge, 2009; Levene, 2010; Walter, 2008).

Webbprestige (web prestige) är måttet på hur många och vilka som länkar till ett objekt på webben. Genom analys av länkar kan ett mått på objektets prestige erhållas och det kan ses som chansen att man hamnar på just den webbsidan vid ett slumpmässigt val. Det mest kända måttet på webbprestige är Googles PageRank, som är en del i Googles rankningsberäkning (Enge, 2009; Langville \& Meyer, 2006; Levene, 2010; Witten et al., 2006).

I figur 5 är de sex findability-koncepten placerade i förhållande till objekt, informationssystem och webben. Tillsammans med figur 4 utgör figur 5 två lager som illustrerar vilka findability-koncept som är av stor betydelse för respektive navigationsstrategi (och vice versa). Exempelvis är tillgänglighet, nåbarhet och webbprestige viktiga vid navigation via länkar, men vid navigation genom användning av en sökmotor är även objektets karaktäristika av stor vikt då sökmotorn relevansberäknar genom att matcha sökorden med objektets innehåll och metadata.

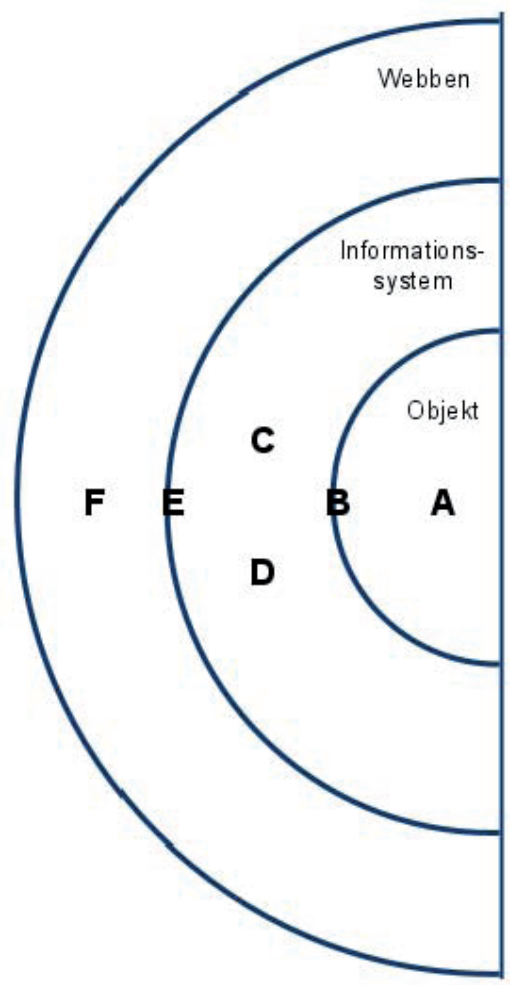

Figur 5. De sex findability-koncepten i relation till objekt, informationssystem och webb.
De sex delkoncepten sammantaget ger en indikation på hur lätt det är att finna ett givet objekt på webben. Findability är summan av delkoncepten och formar ett mått som går att ställa i relation till användning av informationsobjekt och -system. De sex aspekterna av findability kan förutom kopplas till navigationsstrategierna också relateras till informationskompetens, t.ex. till de fyra centrala delkompetenserna vid informationssökning på webben som beskrevs i början (Gerjets \& Hellenthal-Schorr, 2008). Varje aspekt av findability kan ses som en specificering av var och en av delkompetenserna. Exempelvis kan den första av delkompetenserna, Media background knowledge, delas in kunskap kring webbprestige, nåbarhet, osv.

Det går också att jämföra likartade objekts findability i olika informationssystem, t.ex. bilder på en kyrka publicerade i bilddelningstjänsten Flickr respektive i en kulturarvsresurs. Findability, som det är definierat ovan, ger en indikation på hur stor sannolikheten är för att en användare som söker efter bilder på exempelvis en kyrka hittar en viss bild i förhållande till liknande bilder på andra webbplatser.

\section{Diskussion och konklusion}

Problemet som artikeln begreppsmässigt försökt att avtäcka är förhållandet mellan begreppen findability, informationskompetens och informationssökning vid navigation och sökning på webben. Utgångspunkten har varit att informationskompetens är en generisk kompetens där olika aspekter är viktiga $i$ olika medium. Informationskompetensen omsätts i informationssökningsprocessens olika delprocesser med avseende på informationsbehovet. Informationssökningsprocessen är i detta fall interaktion med ett informationssystem på webben och i informationssystemet är objekt lagrade och representerade.

Objekten har också en grad av findability. Findability är ett begrepp som mäter informationsobjekts tillgänglighet på ett strukturellt plan på webben, oberoende av användarens informationsbehov, sökfråga eller informationskompetensnivå. Det består av sex delkoncept som speglar olika delar av relationerna mellan objekt, informationssystem och webben. Findability ser på hela vägen mellan användare och objekt, till de olika möjligheter som användaren har att finna objektet och därmed kan begreppet ses som en mätning ur ett användarperspektiv. 
I och med informationskompetens ses som ett sökfråge-oberoende koncept är det verksamt på samma strukturella plan som findability och det har lett fram till en modell där de kompletteras med sökfråge-beroende koncept, informationsbehovet hos användaren och representationen av innehållet i objekten, som input $\mathrm{i}$ informationssökningsprocessen. Vid navigation och sökning på webben innebär det att informationskompetens och findability är två krafter som verkar åt samma håll och möjliggör att information upptäcks och återfinns. När objekt har låg findability krävs en större informationskompetens av användaren, än för att hitta objekt med hög findability.

Modellen (figur 1) bidrar teoretiskt genom att interaktionen mellan användare och informationssystem delas upp på två plan, ett strukturellt och innehållsmässigt. Det innebär metodmässigt att findability och dess delaspekter kan mätas kvantitativt, oberoende av informationsbehov eller relevansbedömning. Möjligheten att mäta findability leder till att system eller navigationsstrategier kan studeras och utvärderas på ett nytt sätt ur ett användarperspektiv. Därigenom kan designval göras utifrån ökad kunskap om både användarnas beteende och objektens och systemens egenskaper. Både modellen och findability som koncept kan bidra till bättre utformning av undervisning för ökad informationskompetens kring webben, men också generellt då webben i allt större utsträckning är användarnas "hem"-informationsmiljö. Undervisning kring andra informationsmiljöer, såsom fysiska bibliotek och bibliografiska databaser, kan med fördel relateras till webben för att öka användarnas förståelse.

Följderna av låg informationskompetens respektive låg findability är i ett större perspektiv utmaningar för både individ och samhälle. På webben finns enorma informationsmängder (som ökar snabbt) samtidigt som en del aktörer betalar för ökad findability för deras information (kräver resurser). Det innebär att annan information, t.ex. alternativa åsikter eller digitaliserat kulturarv, kan kräva mer ansträngning eller högre informationskompetens för att hittas. Plus att det kan ses som ett existentiellt problem eller som Peter Morville uttrycker det (2005):

"What we find changes who we become."

\section{Kommentar}

Det ramverk som presenteras i artikeln är en del av ett phd-projekt med arbetstiteln The Danish digitalized cultural heritage and its users: Usage, search strategies and findability on the internet, se Fransson (2010) för en introduktion till projektet.

\section{Referenser}

Alpert, J \& Hajaj, N (2008). We knew the web was big... Retrieved 01/17, 2011, from http://googleblog. blogspot.com/2008/07/we-knew-web-was-big.html

Azzopardi, L \& Bache, R (2010). On the relationship between effectiveness and accessibility. Proceeding of the 33rd International ACM SIGIR Conference on Research and Development in Information Retrieval, 889-890.

Azzopardi, L \& Vinay, V (2008). Retrievability: An evaluation measure for higher order information access tasks. Proceeding of the 17th ACM Conference on Information and Knowledge Management, 561570 .

Bashir, S \& Rauber, A (2009). Analyzing document retrievability in patent retrieval settings. Database and Expert Systems Applications, 753-760.

Bates, MJ (1989). The design of browsing and berrypicking techniques for the online search interface. Online Review, 13(5), 407-424.

Bergman, MK (2001). The deep web: Surfacing hidden value. Journal of Electronic Publishing, 7(1), 07-01.

Björneborn, L (2004). Small-world link structures across an academic web space: A library and information science approach. Ph.D. Dissertation. Royal School of Library and Information Science.

Brin, S \& Page, L (1998). The anatomy of a largescale hypertextual web search engine. Computer Networks and ISDN Systems, 30(1-7), 107-117.

Buckland, MK (1991). Information as thing. Journal of the American Society for Information Science, 42(5), 351-360. 
Ding, W \& Lin, X (2010). Information architecture : The design and integration of information spaces. San Rafael, CA: Morgan \& Claypool.

Enge, E (2009). The art of SEO. Sebastopol, CA: O'Reilly.

Fransson, J (2007). Effektivare informationssökning på webben: En handbok $i$ konsten att söka information. Ronneby: HEXA.

Fransson, J (2010). Det danska digitaliserade kulturarvet. Revy, 33(6), s. 8-11.

Gerjets, P \& Hellenthal-Schorr, T (2008). Competent information search in the world wide web: Development and evaluation of a web training for pupils. Computers in Human Behavior, 24(3), 693-715.

Granqvist, H (2003). Mål för informationskompetens. Retrieved 05/01, 2011, from http://www.kirjastot.fi/sv-FI/biblioteksbranschen/rapporter/mal_for informationskompetens/

Halavais, A (2009). Search engine society. Cambridge: Polity Press.

Ingwersen, P \& Järvelin, K (2005). The turn : Integration of information seeking and retrieval in context. Dordrecht: Springer Verlag.

Langville, AN. \& Meyer, CD (2006). Google's PageRank and beyond: The science of search engine rankings. Princeton, N.J.: Princeton University Press.

Levene, M (2010). An introduction to search engines and web navigation. Hoboken, N.J.: John Wiley.

Limberg, L, Sundin, O \& Talja, S (2009). Teoretiska perspektiv på informationskompetens. In J. Hedman, \& A. Lundh (Eds.), Informationskompetenser: Om lärande $i$ informationspraktiker och informationssökning i lärandepraktiker (pp. 36-65). Stockholm: Carlsson.

Marchionini, G (1995). Information seeking in electronic environments. Cambridge: Cambridge Univ. Press.
Marchionini, G (1999). Educating responsible citizens in the information society. Educational Technology, 39, 17-26.

Morville, P (2005). Ambient findability. Sebastopol, CA: O'Reilly.

Morville, P \& Rosenfeld, L (2007). Information architecture for the world wide web. Sebastopol, CA: O'Reilly.

Nachmias, R \& Gilad, A (2002). Needle in a hyperstack: Searching for information on the world wide web. Journal of Research on Technology in Education, 34(4), 475-486.

Pharo, N (2008). Småstegs søkeprosesser: Hvordan "disjointed incrementalism" kan benyttes for å forstå informasjonssøkeatferd. Dansk Biblioteksforskning, 4(2), 33.

Pirolli, P (2007). Information foraging theory: Adaptive interaction with information. Oxford; New York: Oxford University Press.

Sherman, C (2005). Google power : Unleash the full potential of google. New York: McGraw-Hill/Osborne.

Thatcher, J (2006). Web accessibility: Web standards and regulatory compliance. New York: FriendsofED.

Walter, A (2008). Building findable websites : Web standards, SEO, and beyond. Berkeley, CA: New Riders.

White, RW \& Roth, RA (2009). Exploratory search beyond the query-response paradigm. San Rafael, CA: Morgan \& Claypool.

Wikipedia. (2011a). Efficiency. Retrieved 08/31, 2011, from http://en.wikipedia.org/wiki/Efficiency

Wikipedia. (2011b). Findability. Retrieved 05/01, 2011, from http://en.wikipedia.org/wiki/Findability

Wikipedia. (2011c). Kompetens. Retrieved 08/31, 2011, from http://sv.wikipedia.org/wiki/Kompetens 
Wilson, TD (1999). Models in information behaviour research. Journal of Documentation, 55(3), 249-270.

Witten, IH., Gori, M \& Numerico, T (2006). Web dragons : Inside the myths of search engine technology. Boston: Morgan Kaufmann: Elsevier.
Zhang, X, Anghelescu, HGB. \& Yuan, X (2005). Domain knowledge, search behaviour, and search effectiveness of engineering and science students: An exploratory study. Information Research, 10(2), 10-12. 